\title{
Did last-minute change cause loss of \$1-billion Mars probe?
}

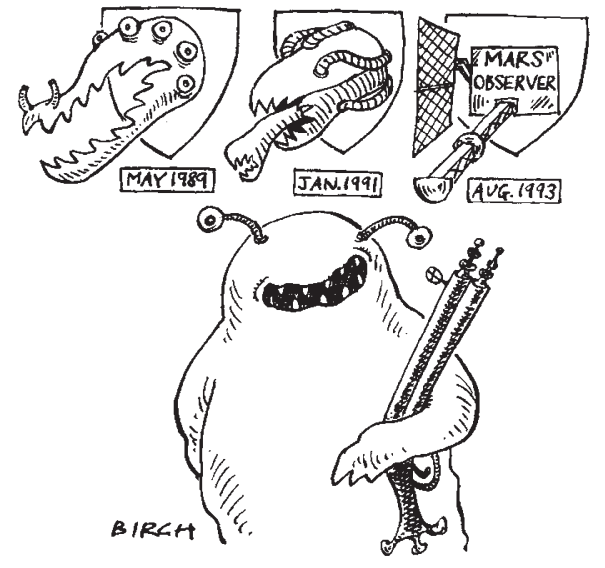

Washington. Senior officials at the US National Aeronautics and Space Administration (NASA) have revealed that loss of contact with the Mars Observer may have been caused by a last-minute decision to fire explosive valves as the probes entered orbit around Mars, instead of 11 months earlier at the launch as originally planned.

\section{IMAGE UNAVAILABLE FOR COPYRIGHT REASONS}

\section{Glenn Cunningham, Mars Observer project manager.}

It was NASA's concern about shockwaves from these pyrotechnic valves equivalent to "tapping the probe with a hammer", according to one NASA engineer that led it to shut down communications with the Mars Observer for five minutes just over a week ago. At the end of last week, NASA had still not been able to contact the probe.

If Mars Observer is lost, the post-mortem may focus on an important change to the mission design, which is said to have been made in May 1992, just three weeks before the probe was shipped from the factory in New Jersey to Cape Canaveral in Florida for its launch.

The change affected the timing of the release of helium from a high-pressure container into two of the probe's fuel tanks, which fed the four thrusters used to manoeuvre the craft. NASA originally planned to release the helium shortly after launch, thereby keeping the fuel pressurized at around 17 bar throughout the mission. This pressure would force fuel - nitrogen tetroxide in one tank, mono methyl hydrozine in the other - into the thrusters for three small manoeuvres during flight and for the major boost in August to push the probe into orbit around Mars.

But three weeks before launch, the project team decided to pre-pressurize the fuel tanks at 17 bar before launch, and to rely on this pressure for the three small manoeuvres. The helium tank, they decided, would be used only to pressurize the fuel just before the final boost into the Mars orbit, by releasing the four pyrotechnic valves (two on each helium pipe).

The team took this action because they were concerned that helium might leak through the regulator valves, designed to maintain fuel tank pressure at 17 bars, and cause a pressure build-up during the 11month cruise to Mars - there had been problems on other missions and during tests.

Engineers usually choose pyrotechnic valves for their reliability: unlike tap valves, they cannot jam closed, because they use a small explosive that pushes aside the metal plate that blocks fluid flow. But using pyrotechnic valves on probes such as the Mars Observer carries several risks.

- The physical shock wave from the valve could damage sensitive components: NASA shut down the communications during last month's manoeuvre because it was concerned that the wave might cause arcing in the travelling wave tube of the probe's transmitter.

- The explosive is detonated by a flash of electrical current of several hundred amperes. This charge cannot be earthed and must be routed back to the power source, while avoiding any detour through sensitive electronic equipment.

- The pyro valve itself could malfunction, although this is unlikely, and possibly damage the neighbouring regulator valves that control the pressure of helium release.

Irrespective of whether any of these prob- lems occurred, NASA - who last week named Timothy Coffey, director of research at the Naval Research Laboratory in Washington, DC, as head of the review board to investigate the loss of contact with the Mars Observer -- will want to find out why the project team made a late design change that required breaking communications at such a crucial stage in the mission. Other missions to planets have sought not to break communications once they have been established in case they cannot be re-established. The Observer team will argue that they had already broken communications three times, and that there was no particular reason to anticipate failure on the fourth.

The apparent failure of the $\$ 980$-million Mars Observer mission comes at a bad time for NASA. Congress will fix the critical budget for the space station and the agency's other activities within the next few weeks. One congressional aide says that while this latest mishap is unlikely to influence veteran congressmen with fixed views on the space programme, it may turn newly elected members against NASA.

Colin Macilwain

\section{Lost opportunities cause concern}

As the mission control team at NASA's Jet Propulsion Laboratory (Pasadena, California) struggled last week to re-establish contact with the Mars Observer, scientists worldwide contemplated the possibility that years of work invested in its sophisticated experiments might have come to nothing.

"Mars Observer was planned to produce a scientific database for the whole planet, from the cellar to the attic", says Bevin French, chief programme scientist. Geophysicists and climatologists in particular hoped that data from its various instruments would improve their understanding not only of Mars but also of the Earth by providing badly needed reference points to include in models of planetary behaviour.

"What we'd really like to do", explains Fred Taylor, professor of atmospheric physics at the University of Oxford, "is to double the Earth's carbon dioxide or raise the temperature by a few degrees, and see what happens. But of course we can't do that, so we look at Mars instead." Taylor's department helped to build the infrared radiometer that would have surveyed Mars' climate from Observer. He is making sure that the department has the spare parts to build another instrument if necessary, in the hope that it might be incorporated on another mission such as NASA's Measure. "The Mars Observer science will have to be done", he says defiantly.

At Arizona State University, the $\mathbf{2 0}$ or so scientists and technicians doing support work for the mission's \$28-million thermal emission spectrometer, which would have mapped the minerals on Mars' surface, are dejected. "I feel fairly awful about this", says Dale Noss, a systems programmer working on software to digest data from the instrument. "A lot of us have not slept well" since contact with the probe was lost, he says. C.M. 